\title{
Pollution Control of Nitrate-selective Membrane by the Inner Solution and On-site Monitoring of Nitrate Concentration in Soil
}

\author{
Eisaku NaKao, Yuki Kitazumi, Kenji Kano, and Osamu ShIRAI ${ }^{\dagger}$ \\ Division of Applied Life Sciences, Graduate School of Agriculture, Kyoto University, Kitashirakawa Oiwake, \\ Sakyo, Kyoto 606-8502, Japan
}

\begin{abstract}
A liquid-membrane type nitrate-selective electrode was improved to lower the influence of contaminants by modifying its inner electrode system from $\mathrm{Ag}|\mathrm{AgCl}| \mathrm{Cl}^{-}$to $\mathrm{Ag} \mid \mathrm{Ag}^{+}$. The $\mathrm{NO}_{3}{ }^{-}$-selective electrode displayed a linear response to the concentration of $\mathrm{NO}_{3}{ }^{-}$with a Nernstian slope of $-53 \pm 1 \mathrm{mV}$ decade ${ }^{-1}$, in the concentration region between $10^{-5}$ and $2 \mathrm{~mol}$ $\mathrm{dm}^{-3}(\mathrm{M})$. The $\mathrm{NO}_{3}{ }^{-}$detection limit was about $10^{-5} \mathrm{M}$. The electrochemical response of this electrode was stable for more than 30 days. The deterioration in responding characteristics due to the coexistence of $\mathrm{Cl}^{-}$was suppressed by use of the $\mathrm{Ag} \mid \mathrm{Ag}^{+}$redox couple in the absence of $\mathrm{Cl}^{-}$inside the $\mathrm{NO}_{3}{ }^{-}$-selective electrode.
\end{abstract}

Keywords Nitrate, tetraheptylammonium ion, ion-selective electrode, monitoring, soil

(Received August 28, 2020; Accepted October 22, 2020; Advance Publication Released Online by J-STAGE October 30, 2020)

\section{Introduction}

Fertilizers containing various elements are required for the cultivation of crops. ${ }^{1-3}$ It is well known that 17 kinds of elements are essential for the growth of plants. ${ }^{4-6}$ Especially, the three elements of nitrogen, phosphorus and potassium are very significant from the viewpoint of the yield of crops, and they are called the three major elements of fertilizer. In agriculture, fertilization has been conducted to improve the yield of crops, but excessive fertilization causes adverse effects on the environment. Since it has because a social problem all over the world, it is necessary to control of fertilization from the standpoint of environmental protection.

Nitrogen is the most indispensable element in the growth period of plants and exists in the natural world as inorganic compounds, such as nitrate $\left(\mathrm{NO}_{3}^{-}\right)$, nitrite $\left(\mathrm{NO}_{2}^{-}\right)$, and ammonium ions $\left(\mathrm{NH}_{4}{ }^{+}\right)$, or organic compounds, such as amino acids, peptides, and proteins. ${ }^{7}$ Because plants mainly absorb $\mathrm{NO}_{3}{ }^{-}$and $\mathrm{NH}_{4}{ }^{+}$, chemical fertilizers containing these ions are often used. It is realized that $\mathrm{NO}_{3}{ }^{-}$tends to escape from farmlands due to the negative charge of soil particles. ${ }^{8,9}$ Since excess $\mathrm{NO}_{3}{ }^{-}$is usually fertilized, eutrophication of the groundwater and water of rivers, lakes, marshes, and seas is a social problem worldwide. It is well known that methemoglobinemia, which is a neonatal disease, comes from $\mathrm{NO}_{3}{ }^{-}$in food and drink. ${ }^{10}$ Since the eutrophication and damage was caused by excessive fertilization of $\mathrm{NO}_{3}{ }^{-}$and/or $\mathrm{NH}_{4}{ }^{+}$, improvement of monitoring methods to measure the concentration of $\mathrm{NO}_{3}{ }^{-}$in environmental water is required. In addition, the construction of a monitoring device of $\mathrm{NO}_{3}^{-}$will help in the development of a hydroponic culture system used at plant factories furthermore.

$\dagger$ To whom correspondence should be addressed.

E-mail: shirai.osamu.3x@kyoto-u.ac.jp
Chromatography, ${ }^{11}$ spectroscopy, ${ }^{12}$ colorimetry, ${ }^{13}$ electroconductometry, ${ }^{14}$ and electrochemical measurements using an ion-selective electrode (ISE) $)^{15-18}$ and others are known as detection methods of nitrate. As for chromatography and spectroscopy, they need large-scale apparatus and pretreatment, such as sampling, filtration, and addition of a certain type of reagent. Accordingly, they are not suitable for in-situ analysis and/or monitoring for the concentration of $\mathrm{NO}_{3}{ }^{-}$. Although an electroconductometer is inexpensive, portable, and easy to use, it is difficult to evaluate the concentration of $\mathrm{NO}_{3}{ }^{-}$exactly because of the coexistence of various ions in sample solutions. Electrochemical devices using ISE are inexpensive and portable, and do not require pretreatment. Although $\mathrm{NO}_{3}{ }^{-}$-ISEs having good responding characteristics have been developed, ${ }^{15-17}$ it is difficult to apply them for practical use because of the change in function over time.

In the present study, a $\mathrm{NO}_{3}{ }^{-}$-ISE using a $\mathrm{PVC}$ membrane immersed in an NPOE solution containing tetraheptylammonium $\left(\mathrm{THA}^{+}\right)$nitrate was improved. In the case of monitoring the environmental water (or soil), $\mathrm{NO}_{3}{ }^{-}$of the selective membrane is gradually replaced by coexisting anions (especially $\mathrm{Cl}^{-}$) around the sensor. This causes deterioration of the selectivity of the sensor. When the concentration of $\mathrm{NO}_{3}{ }^{-}$is measured in the range from $10^{-6}$ to $10^{-3} \mathrm{M}$, this effect is clearly observed. ${ }^{19}$ Since the inner solution of the $\mathrm{NO}_{3}^{-}$-ISE contained only nitrate salts in the present study, other anions distributed in the selective membrane were spontaneously replaced by $\mathrm{NO}_{3}{ }^{-}$within the inner solution. In addition, electrolyte species in the salt bridge between the reference electrode and the sample solution were examined to reduce the interference in measurements due to the existence of ions like $\mathrm{K}^{+}$and $\mathrm{Cl}^{-}$. 

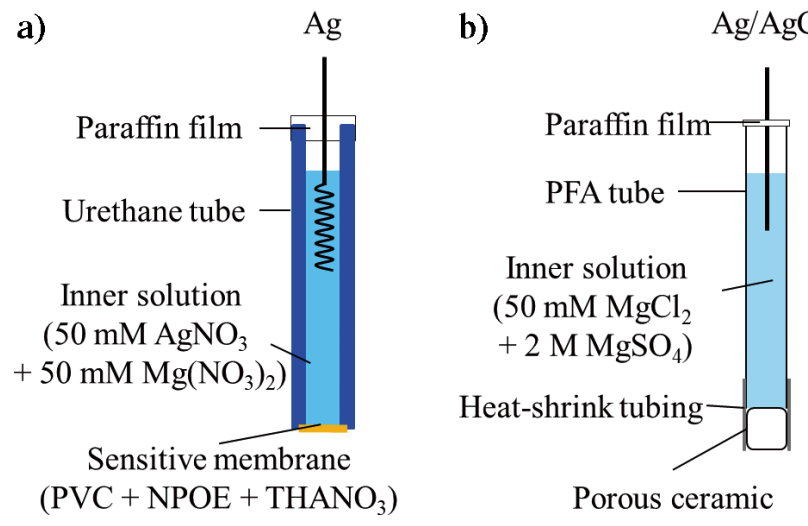

Fig. 1 Schematics of a) $\mathrm{NO}_{3}^{-}$-ISE and b) a reference electrode.

\section{Experimental}

\section{Chemicals}

$\mathrm{LiCl}, \mathrm{LiNO}_{3}, \mathrm{Li}_{2} \mathrm{SO}_{4}, \mathrm{NaCl}, \mathrm{NaNO}_{3}, \mathrm{Na}_{2} \mathrm{SO}_{4}, \mathrm{Na}_{2} \mathrm{HPO}_{4}$, $\mathrm{NaH}_{2} \mathrm{PO}_{4}, \mathrm{KCl}, \quad \mathrm{KNO}_{3}, \mathrm{~K}_{2} \mathrm{SO}_{4}, \mathrm{MgCl}_{2}, \mathrm{MgSO}_{4}, \mathrm{AgNO}_{3}$, tetrahydrofuran (THF), and $\mathrm{PVC}$ were purchased from Wako Pure Chemical Ind., Ltd. The bromide salt of THA ${ }^{+}$(THABr) was bought from Tokyo Chemical Industry Co. Ltd. NPOE was obtained from Dojindo Molecular Technologies, Inc. GR reagent (Kishida Kagaku) was used for spectrophotometric determination of $\mathrm{NO}_{3}{ }^{-}$. The concentration of $\mathrm{NO}_{3}{ }^{-}$in soil was evaluated according to the conventional procedure using a UV-Vis spectrophotometer (Shimadzu, MultiSpec-1500). ${ }^{20,21}$ All chemicals were reagent grade and were used without further purification.

The nitrate salt of $\mathrm{THA}^{+}\left(\mathrm{THANO}_{3}\right)$ was produced by mixing an ethanol solution containing $\mathrm{THABr}$ with that containing excess $\mathrm{AgNO}_{3} .{ }^{19}$ Then $\mathrm{AgBr}$ precipitated from the solution was removed by filtration. By adding pure water to the filtrate containing $\mathrm{THANO}_{3}$ while heating to about $70^{\circ} \mathrm{C}, \mathrm{THANO}_{3}$ precipitated in the filtrate. The white solid $\mathrm{THANO}_{3}$ was separated from the solution via filtration, and it was washed with pure water several times to remove residual $\mathrm{AgNO}_{3}$. It was then dried under vacuum for several hours.

All the aqueous solutions were prepared using high-purity water $(\sigma=18.2 \mathrm{M} \Omega \mathrm{cm})$.

\section{Apparatus}

The electrochemical cell utilized in this study is presented in Fig. S1a (Supporting Information), and it was also used as a hydroponic vessel. The potential between the $\mathrm{NO}_{3}{ }^{-}$-sensing electrode and the reference electrode was measured using a handmade electrometer using an instrumentation amplifer (Texas Instruments Inc., INA116) and an A/D converter (Graphtec Corp., Midi Logger GL 900).

All measurements were performed at $25 \pm 1{ }^{\circ} \mathrm{C}$.

\section{Preparation of the nitrate-selective electrode}

As a structural material for the $\mathrm{NO}_{3}^{-}$-ISE, a urethane tube (inner diameter: $4 \mathrm{~mm}$, outer diameter: $6 \mathrm{~mm}$, length: about $10 \mathrm{~cm}$ ) was used. A sensitive membrane was attached to one end of this tube. An aqueous solution containing $50 \mathrm{mM} \mathrm{AgNO}_{3}$ and $50 \mathrm{mM} \mathrm{Mg}\left(\mathrm{NO}_{3}\right)_{2}$ was used as an internal solution. $\mathrm{A} \mathrm{Ag}$ wire (diameter: $0.5 \mathrm{~mm}$ ) was inserted into the internal solution and fixed with a paraffin film, as shown in Fig. 1a. The composition of the $\mathrm{NO}_{3}{ }^{-}$-sensitive membrane was made of the mass ratios of PVC, NPOE, and $\mathrm{THANO}_{3}$ set to be 0.2:0.4:0.001, respectively. These were dissolved in $2 \mathrm{~mL}$ of THF $(1 \mathrm{~mL}$ per $0.1 \mathrm{~g}$ of $\mathrm{PVC}$ ) and used to prepare the $\mathrm{NO}_{3}^{-}$-sensitive membrane. Approximately $50 \mu \mathrm{L}$ of the THF solution was dropped on a flat glass plate with a syringe, and THF evaporated day and night. After peeling the membrane off, the membrane was fixed to the end of the urethane tube with a small amount of the THF solution.

\section{Preparation of the reference electrode}

An overview of a reference electrode (RE) is indicated in Fig. 1b. The RE was prepared by fixing a porous ceramic block (diameter: $2.7 \mathrm{~mm}$, length: $5 \mathrm{~mm}$, ZR-11 Muff rod, Nikkato Co. Ltd.) to one end of a perfluoroalkoxyalkane (PFA) tube with a heat shrink tube. An aqueous solution containing $50 \mathrm{mM} \mathrm{MgCl}_{2}$ and $2 \mathrm{M} \mathrm{MgSO}_{4}$ was used as an internal solution and a silver wire coated with $\mathrm{AgCl}$ (hereinafter referred to as the $\mathrm{Ag} \mid \mathrm{AgCl}$ electrode) was inserted and fixed with a paraffin film.

\section{Results and Discussion}

\section{Improvement of the reference electrode}

Because it became clear that the potential response of the $\mathrm{NO}_{3}{ }^{-}$-selective membrane was inhibited by the presence of $\mathrm{Cl}^{-}$ concentrations of $>10^{-3} \mathrm{~mol} \mathrm{dm}^{-3}$, an aqueous solution saturated with $\mathrm{MgSO}_{4}$ was used as a junction between the inner solution of the $\mathrm{AglAgCl}$ electrode and a test solution. Here, $\mathrm{MgSO}_{4}$ was utilized as an electrolyte because it is nontoxic and the liquid junction potential within the passage of the porous ceramic was almost constant. Although the potential of the double junctiontype RE used in the previous study was very stable, ${ }^{19}$ the electrode structure was complicated and the Nafion membrane was often broken. The structure of the RE in the present study was very simple, and it is easy to make the electrodes. In addition, the potential shift of the RE was as small as the RE used in the previous study. The potential of the RE indicated about $+10 \mathrm{mV}$ to the calomel electrode, and its fluctuation was about several $\mathrm{mV}$ per day at maximum. The potential fluctuation of the RE was within $\pm 10 \mathrm{mV}$ during the first 30 days.

\section{Characteristics of the $\mathrm{NO}_{3}{ }^{-}$-sensor}

Electrochemical measurements were carried out using the aqueous solution of $5.0 \times 10^{-7} \mathrm{M}$ to $1 \mathrm{M} \mathrm{Mg}\left(\mathrm{NO}_{3}\right)_{2}$. The calibration curve of the $\mathrm{NO}_{3}{ }^{-}$-ISE was measured from the lowconcentration side. After the sensor was washed with pure water and the surface was wiped off, each measurement was conducted. In the $\mathrm{NO}_{3}{ }^{-}$concentration region higher than $10^{-3} \mathrm{M}$, the response time was shorter than $10 \mathrm{~s}$. Even when the concentration of $\mathrm{NO}_{3}{ }^{-}$was lower than $10^{-5} \mathrm{M}$, the response time was within $60 \mathrm{~s}$. Measurement time was $120 \mathrm{~s}$ for each measurement and the average value of the potential $(E)$ obtained from 60 to $120 \mathrm{~s}$ was finally recorded. Figure 2 shows the potential response of the $\mathrm{NO}_{3}^{-}$-ISE. The $\mathrm{NO}_{3}^{-}$-ISE indicated a

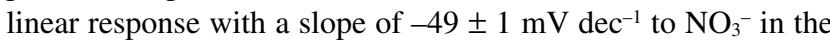
concentration range from $10^{-5}$ to $0.1 \mathrm{M}$. In addition, the $\mathrm{NO}_{3}^{-}-$ ISE showed a nearly linear response in the high concentration range up to $2 \mathrm{M}$, as shown in Fig. S2. The detection limit was experimentally estimated at about $10^{-5} \mathrm{M}$. The $E$ value is expressed by Eq. (1).

$$
E=(0.367 \pm 0.001)-(0.049 \pm 0.001) \log \left(c_{\mathrm{NO}_{3}} / \mathrm{mol} \mathrm{L}^{-1}\right)
$$

Here, $c_{\mathrm{NO}_{3}^{-}}$is the concentration of $\mathrm{NO}_{3}{ }^{-}$.

On the other hand, each ISE was found to actually respond to activity rather than concentration. Therefore, the activity of 


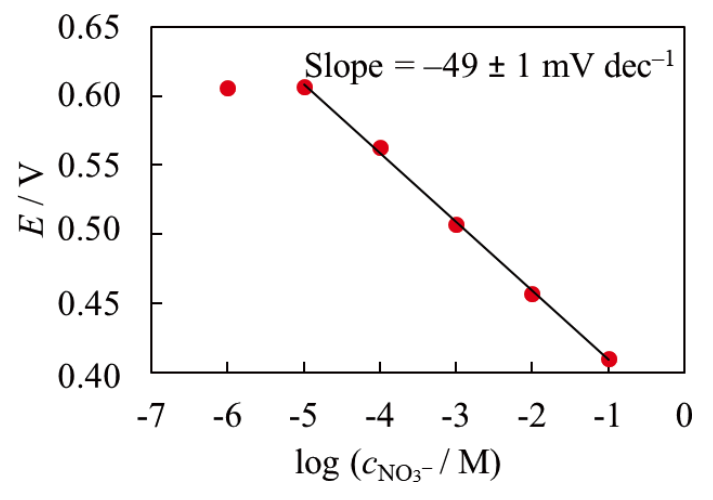

Fig. 2 Calibration curve of the $\mathrm{NO}_{3}{ }^{-}$-ISE. Electrolyte: $\mathrm{NaNO}_{3}$.

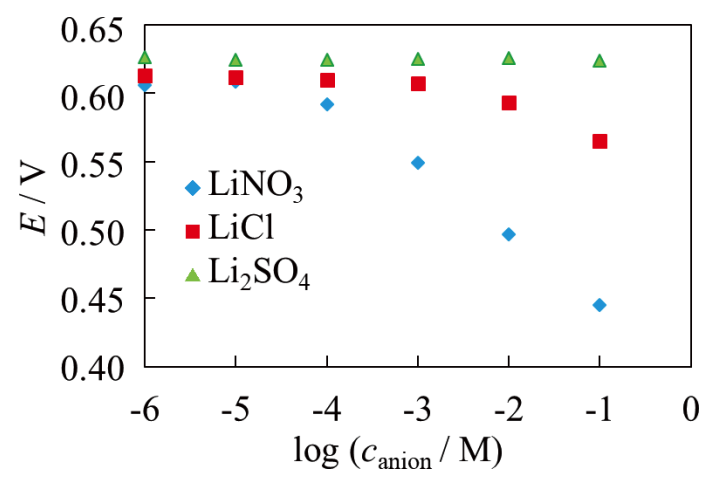

Fig. 3 Dependence of the potential of the $\mathrm{NO}_{3}^{-}$-ISE on the concentration of coexisting anions. Electrolytes: $\mathrm{LiNO}_{3}, \mathrm{LiCl}, \mathrm{LiSO}_{4}$.

$\mathrm{NO}_{3}{ }^{-}$in each solution was calculated and the ISE potential was linearly changed with its logarithm. Here, using the activity constant of $\mathrm{NO}_{3}{ }^{-}, \gamma$, the activity of $\mathrm{NO}_{3}{ }^{-}, a_{\mathrm{NO}_{3}}$, in the aqueous solution can be defined by the following equation,

$$
a_{\mathrm{NO}_{3}^{-}}=\gamma-c_{\mathrm{NO}_{3}^{-}}
$$

The mean activity coefficient, $\gamma_{ \pm}$, is expressed by Eq. (3) based on the Debye-Hückel rule. ${ }^{22}$

$$
\log \gamma_{ \pm}=\frac{A z_{+} z_{-}-\sqrt{I}}{1+B d \sqrt{I}}+b I
$$

Here, $A=0.509 \mathrm{~mol}^{-1 / 2}(298 \mathrm{~K}), B=0.3291 \times 10^{8} \mathrm{~cm}^{-1} \mathrm{~mol}^{-1 / 2}$ $\mathrm{kg}^{1 / 2}, d=3.78 \times 10^{-8} \mathrm{~cm}^{23} z_{+}\left(\right.$charge number of $\left.\mathrm{Mg}^{2+}\right)=+2, z_{-}$ (charge number of $\mathrm{NO}_{3}^{-}$) $=-1, I$ (ion strength of $\mathrm{Mg}\left(\mathrm{NO}_{3}\right)_{2}$ solution) $=1.5 c_{\mathrm{NO}_{3}}, b=0.055 \mathrm{~mol}^{-1} \mathrm{~kg}$. By use of $a_{\mathrm{NO}_{3}^{-}}$derived from Eqs. (2) and (3), the slope of Eq. (1) is $-53 \pm 1 \mathrm{mV} \mathrm{dec}{ }^{-1}$, which is more close to the theoretical value $\left(-59 \mathrm{mV} \mathrm{dec}^{-1}\right)$. The potential responses of the $\mathrm{NO}_{3}{ }^{-}$-ISE against the concentration and activity are shown in Fig. S1b. Since not only $\mathrm{NO}_{3}{ }^{-}$but also many kinds of cations and anions usually exist in the soil environment or culture solution, it is difficult to evaluate the accurate activity of $\mathrm{NO}_{3}{ }^{-}$. Therefore, Eq. (1) is used for the evaluation of $c_{\mathrm{NO}_{3}}$ in the sample solution.

\section{Influence of coexisting ions}

Figure 3 indicates the potential responses of the $\mathrm{NO}_{3}{ }^{-}$-ISE to three anions $\left(\mathrm{NO}_{3}{ }^{-}, \mathrm{Cl}^{-}\right.$, and $\left.\mathrm{SO}_{4}{ }^{2-}\right)$. As for $\mathrm{Cl}^{-}$, the negative shift of the potential of the $\mathrm{NO}_{3}{ }^{-}$-ISE was observed in the

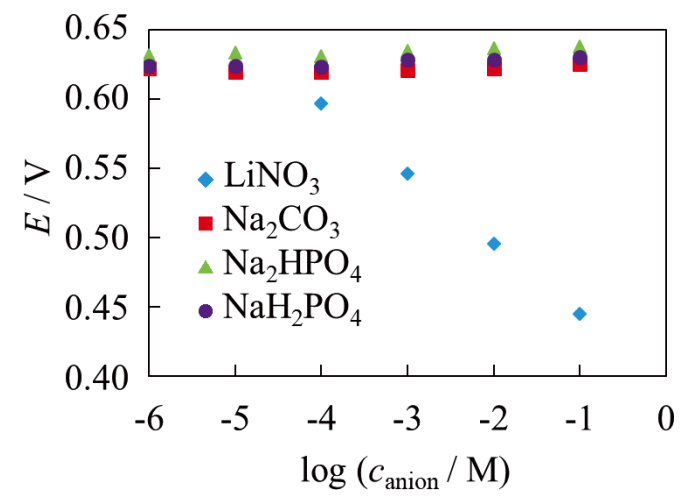

Fig. 4 Dependence of the potential of the $\mathrm{NO}_{3}^{-}$-ISE on the concentration of coexisting anions. Electrolytes: $\mathrm{LiNO}_{3}, \mathrm{Na}_{2} \mathrm{CO}_{3}$, $\mathrm{Na}_{2} \mathrm{HPO}_{4}, \mathrm{NaH}_{2} \mathrm{PO}_{4}$.

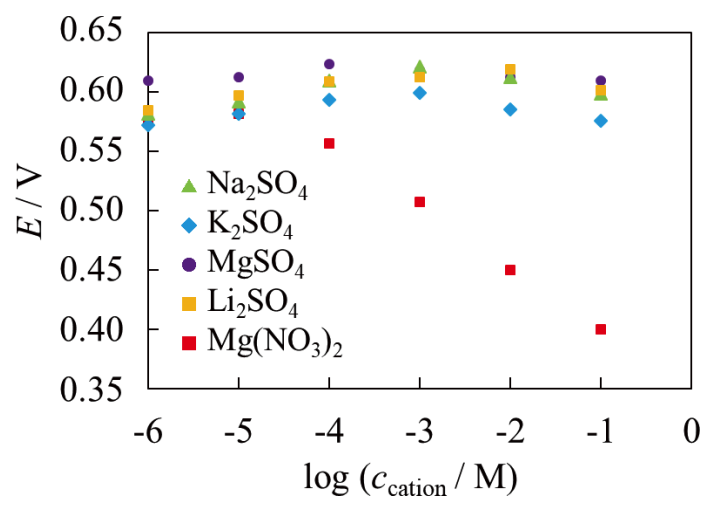

Fig. 5 Dependence of the potential of the $\mathrm{NO}_{3}{ }^{-}$-ISE on the concentration of coexisting cations. Electrolytes: $\mathrm{Na}_{2} \mathrm{SO}_{4}, \mathrm{~K}_{2} \mathrm{SO}_{4}$, $\mathrm{MgSO}_{4}, \mathrm{Li}_{2} \mathrm{SO}_{4}, \mathrm{Mg}\left(\mathrm{NO}_{3}\right)_{2}$.

concentration region of more than $10^{-3} \mathrm{M}$. The potential response of the $\mathrm{NO}_{3}{ }^{-}$-ISE was not affected by the existence of $\mathrm{SO}_{4}{ }^{2-}$. Similarly, the potential responses of the $\mathrm{NO}_{3}{ }^{-}$-ISE were not affected by the other three anions $\left(\mathrm{CO}_{3}{ }^{2-}, \mathrm{H}_{2} \mathrm{PO}_{4}^{-}\right.$, and $\mathrm{HPO}_{4}{ }^{2-}$ ), as shown in Fig. 4. On the other hand, the potential of the $\mathrm{NO}_{3}{ }^{-}$-ISE responded to $\mathrm{K}^{+}$in the presence of more than $10^{-3} \mathrm{M}$ $\mathrm{K}^{+}$, as presented in Fig. 5. The influence of the coexisting ion on the resting potential of the $\mathrm{NO}_{3}{ }^{-}$-ISE $\left(E_{\mathrm{ISE}}\right)$ is evaluated by the Nicolsky-Eisenman equation, as expressed by Eq. (4). ${ }^{24}$

$$
E_{\mathrm{ISE}}=E_{\mathrm{i}}^{\circ}+\frac{R T}{z_{\mathrm{i}} F} \ln \left(a_{\mathrm{i}}+\sum_{\mathrm{j} \neq \mathrm{i}} k_{\mathrm{il}}^{\text {pot }} a_{\mathrm{j}}^{\frac{z_{\mathrm{i}}}{Z_{j}}}\right)
$$

Here, $E_{\mathrm{i}}^{\circ}$ is a constant value that depends on the properties of an objective ion $i$ and on the cell composition, $a_{\mathrm{i}}$ and $a_{\mathrm{j}}$ are the activities of the ions $i$ and $j, z_{\mathrm{i}}$ and $z_{\mathrm{j}}$ are the charge numbers of $i$ and $j, F$ is the Faraday constant, $k_{\mathrm{ij}}{ }^{\mathrm{pot}}$ is the selectivity coefficient of $j, R$ is the gas constant, and $T$ is the temperature. The $k_{\mathrm{NO}_{3}{ }^{-} \mathrm{jot}}$ values for $\mathrm{Cl}^{-}, \mathrm{SO}_{4}{ }^{2-}, \mathrm{HCO}_{3}^{-}$(at $\mathrm{pH} 7$ ), $\mathrm{H}_{2} \mathrm{PO}_{4}^{-}$(at $\mathrm{pH}$ 6), and $\mathrm{HPO}_{4}{ }^{2-}$ (at $\mathrm{pH} 8.5$ ) previously reported by the author's research group are 0.01, 0.0009, 0.0007, 0.0005, and 0.0006, respectively. ${ }^{19}$ Figure 3 shows the potential responses of the $\mathrm{NO}_{3}{ }^{-}$-ISE to $\mathrm{Li}^{+}$salt of $\mathrm{NO}_{3}^{-}, \mathrm{Cl}^{-}$, and $\mathrm{SO}_{4}{ }^{2-}$, respectively. Although $\mathrm{SO}_{4}{ }^{2-}$ did not affect the $\mathrm{NO}_{3}{ }^{-}$-ISE at all, the influence of $\mathrm{Cl}^{-}$appeared around $10^{-3} \mathrm{M}$ and above. Based on the Nikolsky-Eisenman equation, $k_{\mathrm{NO}_{3}{ }^{-} \mathrm{Cl}}{ }^{\mathrm{pot}}$ is evaluated with 0.01 


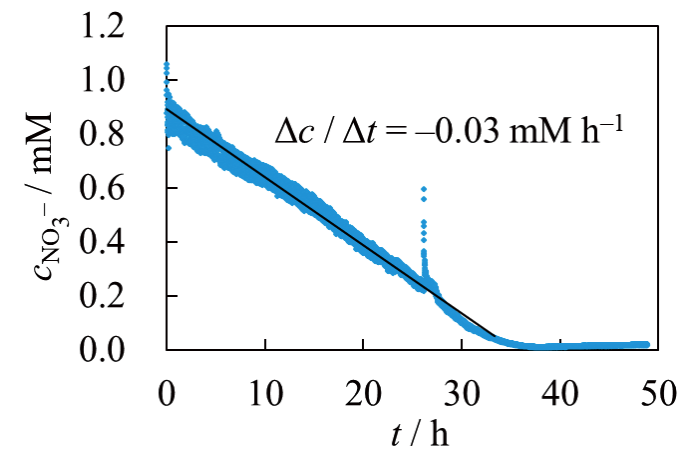

Fig. 6 Time courses of the concentration of $\mathrm{NO}_{3}^{-}$in the culture solution during hydroponic cultivation. Initial concentration of $\mathrm{NO}_{3}^{-}$: $1.0 \mathrm{mM}$. Initial volume of the culture solution: $200 \mathrm{~mL}$. Temperature: $25^{\circ} \mathrm{C}$.

( $i=\mathrm{NO}_{3}^{-}, j=\mathrm{Cl}^{-}$) and it is in good agreement with the previous value. In the present case, the $k_{\mathrm{NO}_{3} \mathrm{SO}_{4}{ }^{2} \text { pot }}$ value is less than $10^{-4}$. Figure 4 indicates the potential response of the $\mathrm{NO}_{3}{ }^{-}$-ISE to the other anions such as $\mathrm{CO}_{3}{ }^{2-}, \mathrm{HPO}_{4}^{2-}$, and $\mathrm{H}_{2} \mathrm{PO}_{4}^{--}$that often exist in the natural environment. Thus, these hydrophilic anions did not interfere with the $\mathrm{NO}_{3}{ }^{-}$-ISE. Figure 5 expresses the potential response of the $\mathrm{NO}_{3}^{-}$-ISE to salts of $\mathrm{SO}_{4}^{-}$. It turned out that $\mathrm{K}^{+}$ affected the $\mathrm{NO}_{3}{ }^{-}$-ISE around $10^{-2} \mathrm{M}$, while $\mathrm{Mg}^{2+}$ did not have an influence, similarly to $\mathrm{Na}^{+}$. That is, the $k_{\mathrm{NO}_{3} \mathrm{~K}^{+}}{ }^{\text {pot }}$ value was estimated at about $10^{-3}$. As for anion-selective electrodes, the selectivity is usually evaluated for coexisting anions, but it is suggested that some kinds of coexisting cations can also influence the liquid-membrane type ISE.

\section{Real-time monitoring}

The variation of the concentration of $\mathrm{NO}_{3}{ }^{-}$in the culture solution owing to the intake by a green plant, chrysanthemum coronarium (Glebionis coronaria), was monitored. The root of chrysanthemum coronarium was immersed in the culture solution ( $200 \mathrm{~mL}$ of tap water containing $1 \mathrm{mM} \mathrm{KNO}_{3}$ ), and the $\mathrm{NO}_{3}{ }^{-}$-ISE and $\mathrm{RE}$ were inserted in the culture solution, as shown in Fig. S1b. The temperature was kept at $25^{\circ} \mathrm{C}$ using a plant incubator (Biotron LH200 NK system, Nippon Medical \& Chemical Instruments Co., Ltd.), and the cultivation was carried out under illumination. A control experiment was carried out using the same container containing only tap water. The water volume of the control experiment was varied from 200 to $188 \mathrm{~mL}$. After the cultivation, the volume of the culture solution changed from 200 to $123 \mathrm{~mL}$. The difference seems to be caused by the stomatal transpiration. The weight of the green plant before and after the experiment was measured after wiping off drops of water on the surface. The plant weight increased from 5.14 to $7.68 \mathrm{~g}$ due to the culture. Figure 6 expresses the time-course of the concentration of $\mathrm{NO}_{3}{ }^{-}$in the culture solution during $48 \mathrm{~h}$. In this case, the potential was recorded, as it was. The initial concentration was about $1 \mathrm{mM}$, and it decreased linearly with time. Since the concentration of $\mathrm{NO}_{3}{ }^{-}$rapidly decreased by the absorption and the $\mathrm{NO}_{3}{ }^{-}$concentration locally became heterogeneous, the culture solution was stirred during the real-time monitoring. It seems that the fluctuation of the $\mathrm{NO}_{3}{ }^{-}$concentration during the measurement was caused by the stirring and the absorption of $\mathrm{NO}_{3}{ }^{-}$. After $35 \mathrm{~h}, \mathrm{NO}_{3}{ }^{-}$was almost exhausted. Thus, we succeeded in monitoring the concentration of $\mathrm{NO}_{3}^{-}$in the culture solution in real time. It is thought that $2.5 \times 10^{-3} \mathrm{~g}$ of nitrogen atoms in the culture solution was metabolized and converted to the plant body. The
Table 1 Comparison of the concentration $\left(c_{\mathrm{NO}_{3}} / \mathrm{mM}\right)$ of $\mathrm{NO}_{3}{ }^{-}$of soil samples $1-5$ evaluated by the ISE method with that by spectrophotometric method

\begin{tabular}{lccccc}
\hline \multicolumn{1}{c}{ Method } & Sample 1 & Sample 2 & Sample 3 & Sample 4 & Sample 5 \\
\hline ISE & 17 & 43 & 21 & 43 & 17 \\
Spectroscopy & 20 & 48 & 22 & 37 & 11 \\
\hline
\end{tabular}

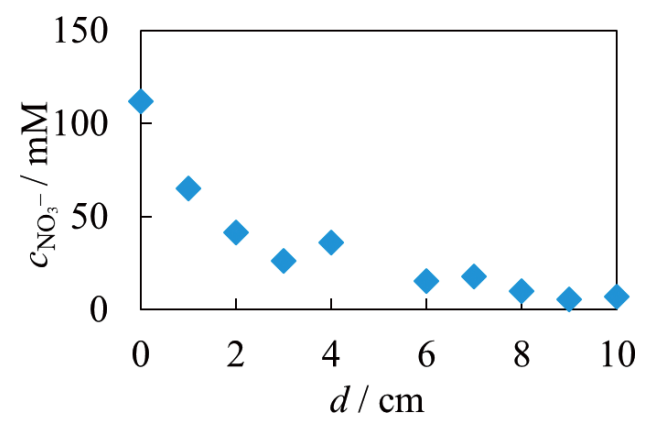

Fig. 7 The concentration of $\mathrm{NO}_{3}{ }^{-}$in soil samples of which depth ranged from 0 to $10 \mathrm{~cm}$. The concentration of $\mathrm{NO}_{3}^{-}$was directly measured by the $\mathrm{NO}_{3}^{-}$-ISE.

weight corresponds to $1.0 \%$ of the total weight change, and it matches with the percentage of nitrogen atoms in general plants. ${ }^{25}$

\section{Measurement of Nitrate Concentration in Soil}

The dry soil sample was prepared as described in the SI. Soil samples were prepared by mixing the dry soil samples with tap water and adding a small amount of $\mathrm{NaNO}_{3}$. The water contents were prepared at about $20 \mathrm{wt} \%$. The concentration of $\mathrm{NO}_{3}$ within the soil samples was directly measured using the $\mathrm{NO}_{3}{ }^{-}-$ ISE and the reference electrode. About $30 \mathrm{~g}$ of a soil sample was measured and then dried at $200^{\circ} \mathrm{C}$ for $24 \mathrm{~h}$. Then, $10 \mathrm{~mL}$ of distilled water was mixed with about $30 \mathrm{~g}$ of each dry soil sample, and the concentration of $\mathrm{NO}_{3}{ }^{-}$of the filtrate was spectrometrically determined by use of a GR reagent. Table 1 shows the concentration of $\mathrm{NO}_{3}{ }^{-}$of five soil samples. There was not a significant difference between the data obtained by the two measuring methods. Thus, the ISE method is very useful and powerful for practical use. The concentration of $\mathrm{NO}_{3}{ }^{-}$in the aqueous solution is often measured by a spectrophotometric method..$^{21,26}$ Since this method requires a considerable amount of time and effort, an alternative method that can measure the concentration of $\mathrm{NO}_{3}{ }^{-}$easily and on-site is required. The ISE method seems to be optimum, because it does not need any pretreatment and the concentration can be directly evaluated.

Soil was filled into a cylindrical vessel (inner diameter: $10 \mathrm{~cm}$, depth: $15 \mathrm{~cm}$ ) that had multiple holes in the bottom, and $1 \mathrm{mM}$ $\mathrm{NaNO}_{3}$ was filled onto a saucer, as shown in Fig. S3. Since the soil usually contains $\mathrm{NO}_{3}{ }^{-}$and water easily evaporates at the surface, it is thought that the concentration of $\mathrm{NO}_{3}{ }^{-}$near the surface was $20-50 \mathrm{mM}$. Next, the depth dependence of the concentration of $\mathrm{NO}_{3}^{-}$was estimated by use of the $\mathrm{NO}_{3}^{-}$-ISE. Figure 7 indicates the depth dependence of the concentration of $\mathrm{NO}_{3}{ }^{-}$of $6 \mathrm{~h}$ later. Although the concentration of $\mathrm{NO}_{3}{ }^{-}$in soil samples with a depth of 9 and $10 \mathrm{~cm}$ is about $3 \mathrm{mM}$, 
the concentration of $\mathrm{NO}_{3}{ }^{-}$around the surface increased. Since the dry soil sample contained $\mathrm{NO}_{3}{ }^{-}$derived from tap water, the $\mathrm{NO}_{3}{ }^{-}$in soil samples was concentrated around the bottom. It is considered that this behavior is caused by drawing water by capillary action and evaporation of water at the surface.

\section{Conclusions}

$\mathrm{NO}_{3}{ }^{-}$-ISE for detecting the concentration of $\mathrm{NO}_{3}{ }^{-}$in the region between $10^{-5}$ and $0.1 \mathrm{M}$ was constructed. Although it is slightly affected by $\mathrm{Cl}^{-}$and $\mathrm{K}^{+}$, no other ions coexisting in the usual environmental water affected the ISE, showing that the $\mathrm{NO}_{3}^{-}$ISE is applicable to real time monitoring. The direct measurement of soil was carried out with this ISE. As for the on-site analytical method, the measurement using optical sensors is well known. ${ }^{27,28}$ Since the concentration of nutrient ions on the soil surface is directly measured, it is very convenient to evaluate the concentration rapidly without needing pretreatment, as with the ISE method. It is thought that the fluctuation of the optical data is larger than those observed by use of the ISE. This might be because the surface condition significantly fluctuates with time.

\section{Acknowledgements}

The authors thank Prof. T. Matoh of Kyoto University for his useful suggestions. This work was supported by the 29th Botanical Research Grant from the ICHIMURA Foundation and a donation from Mr. Nobuo Takeshige.

\section{Supporting Information}

This material is available free of charge on the Web at http:// www.jsac.or.jp/analsci/.

\section{References}

1. S. A. Barber, "Soil Nutrient Bioavalability-A Mechanistic Approach-", 2nd ed., 1995, John Wiley \& Sons, Inc., New York.

2. L. Bernstein, Ann. Rev. Phytopathol., 1975, 13, 295.

3. K. M. Volkmar, Y. Hu, and H. Steppuhn, Can. J. Plant Sci., 1998, $78,19$.
4. A. Shaviv and R. L. Mikkelsen, Fertilizer Res., 1993, 35, 1.

5. R. Uchida, in "Plant Nutrient Management in Hawaii's Soils", ed. J. A. Silva and R. Uchida, 2000, College of Tropical Agriculture and Human Resources, 31.

6. R. L. Mahler, "Nutrients Plants Require for Growth", 2004, University of Idaho, 1.

7. M. Hayatsu, K. Tago, and M. Saito, Soil Sci. Plant Nutrition, 2008, 54,33

8. M. Sebilo, B. Mayer, B. Nicolardot, G. Pinay, and A. Mariotti, Proc. Natl. Acad. Sci., 2013, 110, 18189.

9. K. Kumazawa, Nutrient Cysl. Agroecosystems, 2002, 63, 129.

10. L. Fewtrell, Environ. Health Perspectives, 2004, 112, 1371.

11. R. Kissner and W. H. Koppenol, Methods Enzymol., 2005, 396, 61.

12. G. F. Wang, K. Satake, and K. Horita, Talanta, 1998, 46, 671.

13. M. P. N. A. Gent, Hort. Sci., 2003, 38, 222.

14. C. Wardak, Electroanalysis, 2014, 26, 864.

15. G. Högg, O. Lutze, and K. Cammann, Anal. Chim. Acta, 2014, 335, 103.

16. F. Zuther and K. Cammann, Sens. Acutuators, B, 1994, 18, 356.

17. K. J. Sibley, G. R. Brewster, T. Astatkie, J. F. Adsett, and P. C. Struik, "Advances in Measurement Systems", ed. M. K. Sharma, 2012, Intech Open.

18. Y. Li, Q.-L. Yang, M. Chen, M.-H. Wang, and M. Zhang, Sensors, 2019, 19, 4669.

19. Y. Fukao, Y. Kitazumi, K. Kano, and O. Shirai, Anal. Sci., 2018, 34, 1373.

20. M. L. Horton, "Recommended Soil Testing Procedures for the Northeastern United States", 2nd ed., 1995, Northeastern Regional Publication.

21. P. Singh, M. K. Singh, Y. R. Beg, and G. R. Nishad, Talanta, 2019, 191, 364.

22. J. O'M. Bockris and A. K. N. Reddy, "Modern Electrochemistry 1-Ionics-", 2nd ed., 1998, Plenum Press, New York.

23. A. Villard, O. Bernard, and J.-F. Dufrêche, J. Mol. Liquids, 2018, 270, 30.

24. E. Pungor and K. Tóth, Anal. Chim. Acta, 1969, 47, 291.

25. W. L. Latshaw, J. Agric. Res., 1924, 11, 845.

26. A. W. Morris and J. P. Riley, Anal. Chim. Acta, 1963, 29, 272.

27. M. Kodera and S. Shibusawa, Geoderma, 2013, 199, 64.

28. L. Burton, K. Jayachandran, and S. Bhansali, J. Electrochem. Soc., 2020, 167, 037569. 